\title{
Reafirmacija susedstva kroz prostorne prakse regulisanja poželjne prostorne $i$ društvene distanciranosti
}

\author{
Mina Petrović \\ Univerzitet u Beogradu, Filozofski fakultet, Beograd, Srbija \\ e-mail:mipetrov@f.bg.ac.rs
}

\author{
Milica Milojević \\ Univerzitet u Beogradu, Arhitektonski fakultet, Beograd, Srbija \\ e-mail:m.milojevic@arh.bg.ac.rs
}

\begin{abstract}
SAŽETAK Tekst ima za cilj da istraži odnos koncepta stambene zajednice koji je bio razvijen u projektantsko planerskoj praksi gradnje stambenih naselja u periodu dominacije kolektivnih vrednosti i struktura u Beogradu, i prostornih praksi njihovih konkretnih korisnika. Time se teži reafirmaciji pojma susedstva, koji koncept stambenih zajednica dominantan u planiranju velikih stambenih naselja tokom socijalizma nije eksplicitno prepoznavao. U uvodnom delu, najpre se definiše planesrki koncept stambene zajednice a potom i koncept susedstva razvijen u društvenim naukama. Polazna pretpostavka analize je da poštovanje principa teritorijalnog gradijenta u posmatranim rezidencijalnim celinama pruža osnove za razvoj ključnih dimenzija susedstva kao zajednice individualizovanih pojedinaca. U središnjem delu analize, pojam susedstva se dovodi u vezu sa produkcijom prostora, posebno sa pojmom prostornih praksi. Potom se na na konkretnim primerima prostornih praksi u naseljima nastalim tokom socijalizma, ilustruju aktivnosti stanovnika koje generišu kooperativnost i kohezivnost, kreativnost u korišćenju zajedničkih resursa, to jest njihov povratni efekat na projektovane prostorne strukture i njihov kvalitet. Analizirani primeri potvrđuju da se posmatranim planerskim odnosno projektovanim kolektivnim strukturama generišu susedski odnosi u manjim celinama, koje treba podržati u skladu sa očekivanim udruživanjem građana na poslovima upravljanja zajedničkim prostorijama stambenog objekta i pripadajuće parcele, kao i po pitanju organizovanja poslova održavanja prostora od zajedničkog interesa ne samo od strane javnog već i civilnog sektora. U cilju reafirmacije susedstva i rezultirajućih prostornih praksi kao bitnog elementa produkcije prostora, dati su i mogući predlozi u domenu planiranja i projektovanja.
\end{abstract}

Ključne riječi: stambena zajednica, susedstvo, prostorne prakse, distanciranost. 


\section{Uvod: pojam stambene zajednice i pojam susedstva kao društvene zajednice}

Kao i drugi postsocijalistički gradovi, i gradovi sa iskustvom jugoslovenske verzije samoupravnog socijalizma suočavaju se sa izazovima koje donose novi modeli planiranja i upravljanja lokalnim resursima. Tokom socijalizma, održavanje stambenih zgrada kao i svih otvorenih prostora u stambenoj zajednici bilo je u nadležnosti grada (odnosno gradskih komunalnih službi) dok su stanovnici povremeno angažovani u akcijama čišćenja zajedničkih prostorija i pripadajućih dvorišta i igrališta. U Beogradu, i u Srbiji, nakon privatizacije stanova i ukidanja društvene svojine, upravljanje stambenim zgradama preneto je na vlasnike stanova, a nova regulativa, u skladu sa modelom upravljanja koji podrazmeva saradnju javnog i civilnog sektora (Petrović, 2009., 2012.), ne samo da obavezuje stanare da upravljaju zajedničkim prostorijama u granicama stambenog objekta i pripadajuće parcele već pruža mogućnost i da se više stambenih zgrada udruži po pitanju organizovanja poslova održavanja prostora od zajedničkog interesa. ${ }^{1}$ Međutim, stepenovanje „javnosti“, odnosno „privatnosti“ koje podrazumeva različita ograničenja pristupačnosti i kontrole prostora u nadležnosti stanovnika jedne zgrade ili grupacije zgrada nije sistemski organizovano. Na nivou stambene zgrade stanari se više ili manje uspešno organizuju dok je udruživanje više stambenih zgrada još neiskorišćena mogućnost. Ovaj rad ima za cilj da ilustruje da rezidencijalne celine razvijane u skladu sa specifičnim kolektivističkim tipom stambene zajednice socijalističkom kontekstu pružaju neophodne uslove za razvoj prostornih praksi koje imaju osnovna obeležja susedstva. Pri tome, susedstvo se posmatra kao kreativna zajednica individualizovanih pojedinaca i kao najneposredniji nivo mogućeg građanskog aktivizma, u skladu sa zakonskim promenama u održavanju i upravljanju prostorom stambenih naselja.

U fokusu analize su nova stambena naselja projektovana i planirana tokom socijalizma sa ciljem da se postigne ujednačen društveni standard i afirmiše kolektivna potrošnja. Nova stambena naselja u Beogradu planirana su i realizovana prema urbanističkom konceptu stambene zajednice ${ }^{2}$ i upravljačkom modelu mesne zajednice, koja je istovremeno bila jedinica planiranja naselja i administrativna jedinica gradske opštine. Svaka mesna zajednica u novim naseljima imala je obdanište, osnovnu školu, prostore za odmor, igru i rekreaciju svojih stanovnika, pored upravne i administrativne funkcije centar mesne zajednice je obezbeđivao sadržaje kulture, zanatske i usluge svakodnevnog snabdevanja. Prostori zajedničkih aktivnosti dimenzionisani

1 Čl. 27. Zakona o održavanju stambenih zgrada ("Sl. glasnik RS", br. 44/95, 46/98, 1/2001 - odluka USRS, 101/2005 - dr. zakon, 27/2011 - odluka US i 88/2011) koji otvara mogućnost udruživanja više stambenih zgrada oko pitanja od zajedničkog interesa.

2 Koncept stambene zajednice prihvaćen je 1958. godine kao urbanistički obrazac organizovanja mesnih zajednica u gradovima SFRJ. U uspostavljanju teritorijalnosti stambene zajednice stručnjacima je zadato da kroz urbanističke norme i prostornu organizaciju naselja obezbede 'zavođenje reda u zaokruženoj celini'. Namera planera je bila da stambena zajednica predstavlja nedeljivu i nepromenljivu jedinicu teritorije dok veće celine (naselja) nastaju saobraćajnim povezivanjem više stambenih zajednica) (Novak, V.,1958.). Ovaj princip je obezbeđivao konzistentost uslova stanovanja unutar zajednice i etapnost u izgradnji naselja. 
su i pozicionirani u naselju tako da imaju značajnu ulogu i u teritorijalnoj i u društvenoj koheziji stambene zajednice, iako se sam koncept susedstva kao društvene zajednice nije eksplicitno pominjao. Zapravo, koncept stambene zajednice sugerisao je da stanovnici većinu svojih potreba za socijalizacijom realizuju unutar stambenog naselja, tj. na području mesne zajednice (Milojević, 2009.), ne razmatrajući diferenciranje stambene zajednice na uže susedske celine, odnosno diferencirane prakse stanovnika u prisvajanju prostora.

Drugim rečima, planerski koncept stambene zajednice nije eksplicitno prepoznavao pojam susedstva kao specifičnog tipa društvene zajednice čiji je elementarni osnov uspostavljanja odnosa prostorna bliskost $i$ neminounost kontakata, a primarni razlog interakcija je zasnovan na zajedničkim aktivnostima u prostoru na koji su susedi upućeni, a ne nužno i na zajedničkim uverenjima (socijalnaj bliskosti) (Brint, 2001.:12-13). Upućenost stanovnika stambenih naselja na sadržaje i prostore uređene na području mesnih zajednica trebalo je da obezbedi socijalnu kohezivnost na ovom prostornom nivou, ali ne i izdvajanje manjih spontano organizovanih socio-prostornih grupa. Činjenica da su su interakcije u susedstvu obično pod uticajem drugih socijalnih identiteta stanovnika, te da nivoi participacije u zajedničkim aktivnostima, uzajamne pomoći i prisnosti mogu značajno da variraju unutar neke teritorijalne celine (ibidem), posebno je relevantna za konktekst stambenih naselja građenih tokom socijalizma sa planiranom heterogenošću u kvalitetu i strukturi stanova. Zbog režima distribucije stanova tokom socijalizma (kvalitetniji stanovi višim socijalnim grupacijama) i modela potonje privatizacije (Petrović, 2004., 2008.), razlike u kvalitetu stanovanja unutar naselja, značajno korespondiraju socijalnoj pripadnosti korsinika. To nameće mehanizam socio-prostorne distanciranosti u formiranju susedskih odnosa, koji omogućava da se postepeno grade veze poverenja i nalaze novi motivi zajedništva između individualizovanih odnosno različitih aktera. Takve veze, pak, ne korespondiraju nužno sa celinom projektovanih stambenih zajednica to jest naselja, odnosno pretpostavljaju uvažavanje prostorne i društvene distanciranosti u njihovim okvirima. Taj stepen individualizacije i spontanog organizovanja građana u manjim celinama od administrativno predviđenih (mesnih zajednica) nije odgovarala osnovnim principima socijalističkog sistema, što je i uslovilo zapostavljanje ideje susedstva.

Ipak, primenjeni pristup teritorijalnog gradijenta u analizi koncepta stambene zajednice ukazuje i na ove mogućnosti. Naime, teritorija stambene zajednice podeljena je na tri zone različitih uslova i karaktera stanovanja, odnosno stepena javnosti prostora (zona individualizacije, zajednička zona, javna zona), u skaldu sa definisanjem zona na teritorijalnom gradijentu od poluprivatne do javne (Robinson, 2006.:163).

Za razliku od domena javnog gradskog prostora, koji je otvoren za svakoga (na primer glavna ulica, trg i sl.), domen javnog lokalnog prostora je prostor u blizini stambenog sklopa u kojem se može zateći svako ko ima razlog da bude tu, i u opsegu je kontrole lokalne uprave. Tako je, prema idealno tipskom konceptu stambene zajednice, prva zona, neposredno uz centar stambene zajednice, projektovana da označava ulaz, grupacijom stambenih kula sa uređenim otvorenim prostorima visokog stepena javnosti. 
Druga zona je unutrašnji, mirni deo teritorije niže spratnosti, sa više zelenila i većim brojem igrališta, netranzitnog, polujavnog karaktera, prostor u kojem se može zateći svako ko ima razlog da bude tu ali nad kojim neposrednu kontrolu imaju stanari, koji se mogu suprotstaviti prisustvu nepoželjnih lica, i imaju pravo da utvrde režim korišćenja i razgraniče prostor (ograda, interfon, i sl.). Na zajedničkim prostorima ovog tipa nalaze se prilazni putevi, parkinzi, zajedničke deponije, zajedničke garaže, zajednički otvoreni prostori, i sl. (Nikezić, 2007.:86). Ovi prostor mogu se posmatrati u analogiji sa zajedničkim prostorijama u kolektivnoj stambenoj zgradi (stepenište, ulazni hol, zajednička garaža u suterenu ili podrumu i sl.), što Zakon o održavanju stambenih zgrada (Sl. glasnik Republike Srbije“, br. 44/95, 46/98, 1/01.) i čini prepoznajući prava i obaveze korisnika (vlasnici, zakupci) stanova na prostor izvan stana. Takođe, odnos pojedinačnih domaćinstava prema zajedničkom prostoru može se regulisati na način na koji je to učinjeno u kondominijumima koje treba definisati pravnim aktima i zajedničkim dogovorom (Petovar i Mojović, 2006.).

Treća zona u stambenim zajednicama je planirana kao elastično područje individualnih kuća (pozicije integrisanja postojećih struktura individualnog stanovanja koje su tada okruživala periferiju grada i lokacije za nova naselja, koja ima najviše elemenata poluprivatnog prostora. Poluprivatni prostori su prostori direktno pripojeni privatnim posedima, kojima je pristup moguć uz dozvolu vlasnika ili stanara, na primer predbašta, trem, ulaz.

U analitičkom fokusu ovog rada su različite manifestacije neformalnih prostornih praksi stanara koje su se tokom vremena razvile u naseljima građenim prema konceptu stambenih zajednica, a kojima stanari samoinicijativno uspostavljaju i kontrolišu granice prisvojenog ili pripadajućeg prostora u neposrednom okruženju njihovog stana/kuće. Takve prakse podrazumevaju odnos prema susedu i/ili prolaznicima kao drugome, bilo kao prema pojedincu ili grupi. Time se koncept susedstva potvrđuje kao socijalni konstrukt, koji za ljude nastanjene u istom prostoru (stambeno naselje) može uključivati različite socio-prostorne celine (sprat, deo zgrade, stambena zgrada, manje ili veće stambene grupacije), odnosno potvrđuje da se socio-prostorne granice susedstva povlače i prema intenzitetu socijalnih kontakta, prostornoj udaljenosti, režimu javnosti prostora, i sl. Shvatanje susedstva kao zajednice, dakle, ne tumači potrebu za izdvajanjem primarno kao povlačenja od drugih, nego kao prostor slobode koji ne suprotstavlja familijarnost i alijenaciju. Time se istovremeno afirmiše potreba i da se bude sa drugima i da se očuva različitost i razdvojenost, ali uz prepoznavanje zajedničkog prava na socijalni prostor (Tonkiss, 2005.:10). Tako se distanciranost pojavljuje kao ključ društvene relacije među urbanim subjektima, ili, na tragu Zimela (Simmel, 1997.:167), može se reći da ono što izgleda kao disasocijacija u suštini predstavlja osnovnu formu urbane socijacije (povezivanja). Čikaška škola je u urbanim uslovima života videla slom tradicionalnih socijalnih veza, te je afirmisala susedstva kao specifična moralna područja koja doprinose društvenoj koheziji i omogućuju uključivanje u proces svakodnevnog deljenja prostora sa strancima. Lefevr (Lefebvre, 1991.:56) opisuje takvu situaciju pojmom ne-agresionog pakta (pax urbana), nenasilja koje podrazumeva recipriocitet i zajedničku upotrebu prostora sa drugima, koji, iako nepoznati nisu percepirani kao opasnost. Na istom tragu i Jacobs (1964.:126) ukazuje da o urbanom susedstvu ne treba razmišljati kao o prostornoj enklavi već sastavnom delu tokova gradskog života, što je ideja sadržana 
i u principu teritorijalnog gradijenta u stambenim naseljima, o koje je već bilo reči. Ipak, prostorno planerski koncept stambene zajednice implicitno je podrazumevao pojam susedstva kao homogene skupine ljudi koja deli neminovnost življenja na istom tlu, što je značajna redukcija njegovog značenja kao dinamičnog i otvorenog polja socio-prostornih interakcija u kojima se stalno otvaraju nove pozicije, razvijaju nove sposobnosti i nalaze novi motivi zajedničkog delovanja socijalno heterogenih aktera (pojedinaca/grupa).

\section{Potencijali susedstva u velikim stambenim kompleksima: analiza produkcije prostora kroz prostorne prakse}

Predmet pažnje ovog odeljka su intervencije stanovnika u prostoru stambenih naselja građenih po prostornom konceptu stambenih zajednica, a koje nisu rezultat plana, odluke ili zakonske regulative, i koje za posledicu imaju društveno prihvatljivo, pozitivno okarakterisano izdvajanje grupe ili pojedinca u odnosu na okružujuće strukture. Za razumevanje praksi izdvajanja i pripadanja koje doprinose specifičnom stilu života u odnosu na okružujuće, planski zadate okvire kolektivne forme, u ovom odeljku se oslanjamo na Lefevrov koncepta produkcije prostora i Burdijeove pojmove habitusa i polja.

Lefevr (1991.) posmatra urbani prostor ne samo kao okvir strukturiranja društvenih odnosa i procesa već i kao strukuru koja je oblikovana društvenim aktivnostima i značenjima. Društvena produkcija prostora, prema Lefevru, odvija se na tri nivoa. Prvi je nivo reprezentacije prostora, koji se odnosi na koncepcije uređenja prostora (planovi, projekti kojima se racionalizuje prostor grada u skladu sa dominantnim vrednostima). Drugi nivo čine prostorne prakse, a koji uključuje konkretne odnose i rutinske oblike društvene kompetentnosti i delanja društvenih aktera. Treći je nivo reprezentacionih prostora, koji se odnosi na prostore imaginacije, otelovljenja, želje, na življni prostor u kojem akteri iskušavaju zadate strukture dajući im specifična značenja u procesu prisvajanja (Lefevr, 1991.:38-39). Predmet naše analize reflektuje sva tri nivoa, uz naglasak na trećem, no Lefevr, poput Burdijea, akcenat zapravo stavlja na prakse, pomoću kojih obojica naglašavaju specifičnu kompleksnost društvene dinamike (Spasić, 2004.). Otuda ovaj pojam reflektuje sva tri nivoa produkcije prostora, jer prostorne prakse počivaju na dinamičkoj dvostrukosti, s jedne strane su vođene nesvesnim, nenameravanim i predrefleksivnim principima, usvojenim kroz proces socijalizacije u datim strukturnim okvirima (na nivou naselja - operacionalizacijom reprezentacije prostora odnosno plana/projekta), a, s druge, deluju asocijativno i rekonstruktivno, te nisu svodive na mehaničku reakciju provociranu unutar datog prostornog koncepta, čime zapravo produkuju ono što Lefevr naziva reprezentacionim prostorima. Na tragu ovog razmišljanja susedstvo se ukazuje i kao mesto taktičkog otpora odozdo (bottom up tactical resistance) i podrazumeva kreativnu upotrebu javnog prostora kojom stanovnici čine prostor svojim, suprotstavljajući se nametnutom, racionalnom konceptu gradskog prostora (Paterson, 2006., Stevenson, 2003.).

Burdjeovskim rečnikom, susedstvo se, s jedne strane, pokazuje kao složena mreža socijalnih odnosa koja dobija karakteristike specifičnog habitusa (Bourdie, 1990.), 
odnosno postaje stabilna konfiguracija akcija i iskustva, strukturiranih u saglasju sa društvenim položajem i vrednostima aktera, kojom se generiše značajan stepen praktičke kompetentnosti u socijalnom okruženju odnosno omogućava nesvesna selekcija aspekata koji čine okruženje poznatim i prihvatljivim ("našim") (Albrow, 2000.). S druge strane, susedstvo se konstituiše i kao specifično burdijeovsko polje autonomne logike delanja, u kojem akteri saglasno vrednostima (životni stil) koje zastupaju i resursima kojima raspolažu (materijalni-nematerijalni) na njega utiču (Spasić, 2004.), na primer, menjanjem sadržaja, kontrolom sadržaja i sl, odnosno sadejstvom habitusa i polja (i raspoloživih kapitala aktera) dolazimo do rezultirajućih praksi susedstva.

Susedstvo kao arena građanskog aktivizma promišlja se i u odnosu na koncept socijalnih mreža, čija se suština nalazi u sferi praktičnih/materijalnih koristi koje stiču članovi neke zajednice. Na tragu Putnamovog pristupa ističe se da norme i mrežna interakcija koje nastaju iz asocijacija licem u lice omogućuju učesnicima da efektivnije postižu zajedničke ciljeve (Putnam, 1993.). Drugim rečima, rezultirajući društveni kapital generiše dobru volju, poverenje, reciprocitetne odnose i kooperaciju među uključenim akterima, što podiže efikasnost socijalne akcije. Forrest i Kearns (2001.:2140) su izdvojili sledeće domene društvenog kapitala kao preduslove kohezivnosti i adekvatnog društvenog aktivizma na nivou susedstva: pripadanje, sigurnost, poverenje, kolektivne norme i vrednosti, mreže podrške i reciprociteta, asocijativne aktivnosti i zajednički ciljevi, participacija, povećanje moći. U slučaju njihovog izostanka raste nepoverenje, sumnja, opreznost, povlačenje (Hobs, 2006.:65), odnosno fragmentacija i atomizacija susedstva, te izostajaje zajedničko delanje. Kriza zajedništva, atomizacija i stanje anomije označavaju stanje povlačenja građana iz gradskog života, a Oscar Newman je opisao tri karakteristična tipa povlačenja: indiferentnost prema problemu (zapostavljanje problema), prepuštanje nadležnosti institucijama ili službama (propuštanje prilike za sopstvene poduhvate), ograđivanje poseda (izolacija) (Newman, 1973.:14-15). Ovo je posebno relevantno za tranziciona društva, poput srpskog, sa izrazito niskim opštim poverenjem građana u institucije i niskim međusobnim poverenjem različitih društvenih aktera (Cvejić, 2010.), te zbog činjenice da se post-socijalistička transformacija može smatrati i kao transformacija od dominatno pasivnog ka dominatno aktivnom društvu (Etzioni, 1992.). Ukratko, koncept socijalnog kapitala pretpostavlja da su veze ograničene samo na susedstvo korisne ali nedovoljne, te da je socijalni kapital susedstva utoliko razvijeniji i efikasniji ukoliko stanovnici imaju veze i sa drugim susedstvima odnosno gradskim institucijama (Woolcock, 1998.). Te veze nisu samo kanali komunikacije, razmene iskustva, znanja, informacija već se one odnose i na određen prostor, bilo da se radi o prostoru gde se odvija komunikacija bilo da se radi o prostoru kao predmetu dogovora i saradnje.

Ako imamo u vidu da se društvo u Srbiji često povezuje sa stanjem anomije (fragmentacije - nepovezanosti - izolacije u privatne sfere), jer građani retko prepoznaju i brane javno dobro, čak i kada je ono u neposrednoj blizini njihovog stana, potrebno je ukazati na vrednost i ulogu koju prostor može imati ili ima za stimulaciju socijalnih interakcija u stambenom okruženju. Reč je o javnim prostorima koji istovremeno omogućavaju kontakte unutar susedstva kao određene teritorijalne 
zajednice i njegovu integraciju sa drugim urbanim nivoima (ulica, kvart, distrikt, centar naselja, centar grada). Naselja koja su integrisana u gradsku mrežu, koja imaju preglednost prostora (dobru prostornu čitljivost) i prepoznatljiva mesta imaju veći potencijal za razvijanje socijalnih interakcija. U ovom smislu, arhitektonska rešenja materijalizuju povezanost susedstva sa drugim urbanim nivoima i drugim susedstvima. Iz prethodnog teksta očigledno je da zona zajedničkog prostora u stambenim naseljima ne može da bude unapred, planski ili projektom potpuno definisana, kako se to smatralo u periodu nastanka koncepta stambenih zajednica, jer se zajednički prostor konstituiše i kroz akcije stanara, kojim oni regulišu pristup i režima upotrebe određenog prostora. Sa planerske tačke gledišta, pitanje je i da li tako "osvojen" prostor funkcioniše kao autonomna celina u odnosu na grad ili postoji određena mera usaglašavanja sa pravilima datim od šire zajednice/grada? Jedan od mogućih odgovora je fleksibilizacija standarda kao način uvažavanja i autonomnosti susedstva i opštih pravila. Umesto favorizovanja jedne strane, takav pristup omogućava da se u susretu stručnjaka i građana uvaže motivi preduzetih akcija samoregulacije neposrednog okruženja stanara, ali i da se, s druge strane, u okvirima fleksibilne primene standarda artikulišu i susretnu sva tri nivoa produkcije prostora u Lefevrovom značenju. To je naročito relevantno imajući u vidu da se stihijska privatizacija društvene imovine i prepuštanje nadležnosti održavanja i upravljanja stambenim zgradama građanima (civilnom sektoru i privatnom sektoru), odvija bez stručne i institucionalne pomoći, i bez bazične kontrole u uspostavljanju/očuvanju standarda stanovanja.

U cilju grafičkog prikaza dosadašnje rasprave, u Prilogu 1., dat je mogući raspon pozitivnih i negativnih stanja društvene kohezije u susedstvu sa aspekta njenog značaja za lokalni aktivizam. Posebno je definisano područje distanciranosti, čije je granično stanje na negativnom polu podozrenje a na pozitivnom poverenje. Imajući $\mathrm{u}$ vidu ovaj raspon, u daljem tekstu se ispituju prostorne prakse u polujavnom i poluprivatnom prostoru susedstva, koje omogućavaju prelazna stanja - povremenu saradnju i privremeno sadejstvo, kao stanja karakteristična za susedstvo u savremenom društvu.

Prilog 1.1.

Skala društvene kohezije

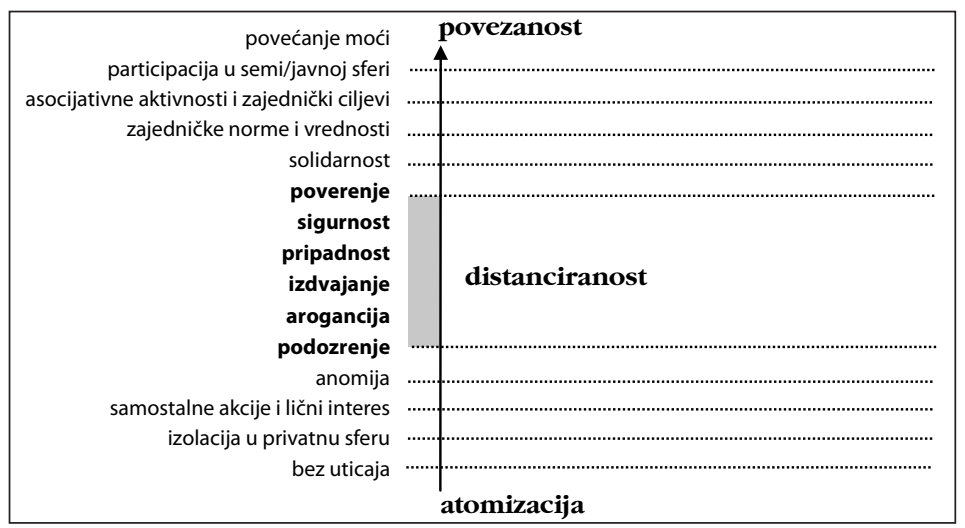


Analiza primera prostornih struktura koje slede nalaze se na različitim pozicijama s obzirom na teritorijalni gradijent prostora: od onih u neposrednoj blizini stambenih objekata - poluprivatnog odnosno polujavnog karaktera, do onih na prometnijim obodnim saobraćajnicama, odnosno na granici polujavnog i javnog prostora. Istraživanje je obavljeno u stambenim zajednicama, ujedno i MZ, novobeogradskih blokovima (45, 62 i 70) i u mesnoj zajednici 5 u beogradskom naselju Šumice. Identifikovane su prakse označavanja prisvojenih površina i kontrole pristupa, nastojanja da se prostor prilagodi i zajedničkim, a ne samo individualnim potrebama i interesima, da se učini atraktivnim i za posetioce, da se odbrani od neželjenih sadržaja (komercijalizacija). Rad na terenu obuhvatao je snimanje novonastalih struktura i razgovore sa lokalnim stanovništvom, sa kojima je kontakt ostvaren nakon snimanja intervencija u prostoru, odnosno traganjem za akterima prostornih praksi koji su ih proizveli. Razgovor je imao za cilj da identifikuje pokretače akcije, motive kojima su se rukovodili, zadovoljstvo postignutim i dalje planove (ako ih ima). Na različitim lokacijama ostvaren je različit broj kontakata sa najaktivnijim stanarima, do trenutka „zasićenja“ traženih informacija. U cilju reafirmacije susedstva i rezultirajućih prostornih praksi kao bitnog elementa produkcije prostora, svaki primer komentarisan je i sa stanovišta fleksibilnijeg pristupa u domenu planiranja i projektovanja.

\subsection{Povezivanje preko zajedničkih resursa - prepoznavanje resursa u blizini (izvan privatnog poseda)}

Prvi primer odnosi se na korišćenje međuprostora u stambenom sklopu atrijumskog tipa u novobeogradskom bloku $70 .{ }^{3}$ Nakon što je jedan stanar prepoznao mogućnost da uredi prostor izvan njegove dvorišne terase radi skupljanja opalog lišća, ošišane trave i orezanog cveća, odnosno pravljenja organskog đubriva za poboljšanje zemljišta i rast biljaka, njegova inicijativa je podržana od većine stanovnika stambene grupacije koja je upućena na isti prostor, te su napravljenu metalni kavezu za prikupljanje zelenog otpada. Kavezi su postavljeni u javnom prostoru, na zelenoj površini uz parking, na mestu koje je dostupno stanovnicima i zaklonjeno od prolaznika. Ova akcija povukla je niz drugih: uređeno je mesta za povremena okupljanja stanara, koje je nazvano ognjište - za komšijski ručak (gde se stanari okupljaju bar jednom mesečno u periodu lepog vremena), stanari dva susedna ulaza dogovorili su mesto za izgradnju fontane, uz već formirano mesto za svakodnevne komšijske kafe (pod lipom). U dogledno vreme, ovo susedstvo će napraviti i botaničku baštu (Prilog 2.1.).

Podrška ovih akcija i njihova realizacija ukazuju da su građani prepoznali odgovornost i za prostor(e) u susedstvu koji nije(su) u njihovom vlasništvu; da se zelenilo

3 Naselje je izgrađeno prema društvenom planu za period 1965 - 1970. i detaljnom urbanističkom planu iz 1966. U skladu sa konceptom stambene zajednice izgrađeni su tipski stambeni sklopovi u tri zone. Umesto zone individualne gradnje formirana je zona niske spratnosti $(\mathrm{P}+2$ i $\mathrm{P}+4)$ sa stambenim sklopovima atrijumskog tipa. Ovaj tip sklopa omogućio je da se u zoni malih gustina naseljenosti ostvari neposredan kontakt sa prirodom, da se tipiziranim objektima obuhvati dvorište - parče prirode prema kojem se orijentišu svi stanovi šest stambenih ulaza. 
lako prepoznaje kao zajednički resurs u blizini stana oko kojeg se pokreću inicijative koje jačaju ekološki odgovorno ponašanje (kompostiranje zelenog otpada) i podižu ekološki kvalitet susedstva, te doprinose jačanju društvene kohezije na nivou susedstva.

Afirmacija uočenih prostornih praksi u postojećim prostornim strukturama mogla bi da obuhvati:

(1) prepoznavanje pozicija zajedničkih resursa;

(2) za prepoznate pozicije ponuditi moguća rešenja "distancera" koji resurse u blizini angažuje na socio-ekološki prihvatljiv način (prikupljanje kišnice i reciklažnog materijala, energije sunca i vetra, gajenje billjaka i sl.).

$\mathrm{Na}$ ovaj način dodatno bi se podržale prakse udruživanja stanara u susedstva unutar stambenih kompleksa, koji su preveliki da bi bili jedno susedstvo, ali koji očigledno pružaju dovoljno podsticaja da stanari prepoznaju zajedničke interese i aktivnosti u polujavnom prostoru na koji su svakodnevno upućeni, u najelementarnijem smislu pogledom iz svojih privatnih stambenih prostora. U urbanističkom smislu, potrebno je prepoznati taj minimalni razmak između privatnog i javnog prostora i osmisliti motiv, stimulus da pored partikularnih interesa susedi vide/uvaže drugog i sličnost interesa sa njim/a, što može biti prvi korak izlaska iz stanja atomizacije i jačanje kohezionih veza na nivou susedstva.

Prilog 2.1.

Kavezi za prikupljanje zelenog otpada; Ognjište; Mesto za komšijske kafe "pod lipom"
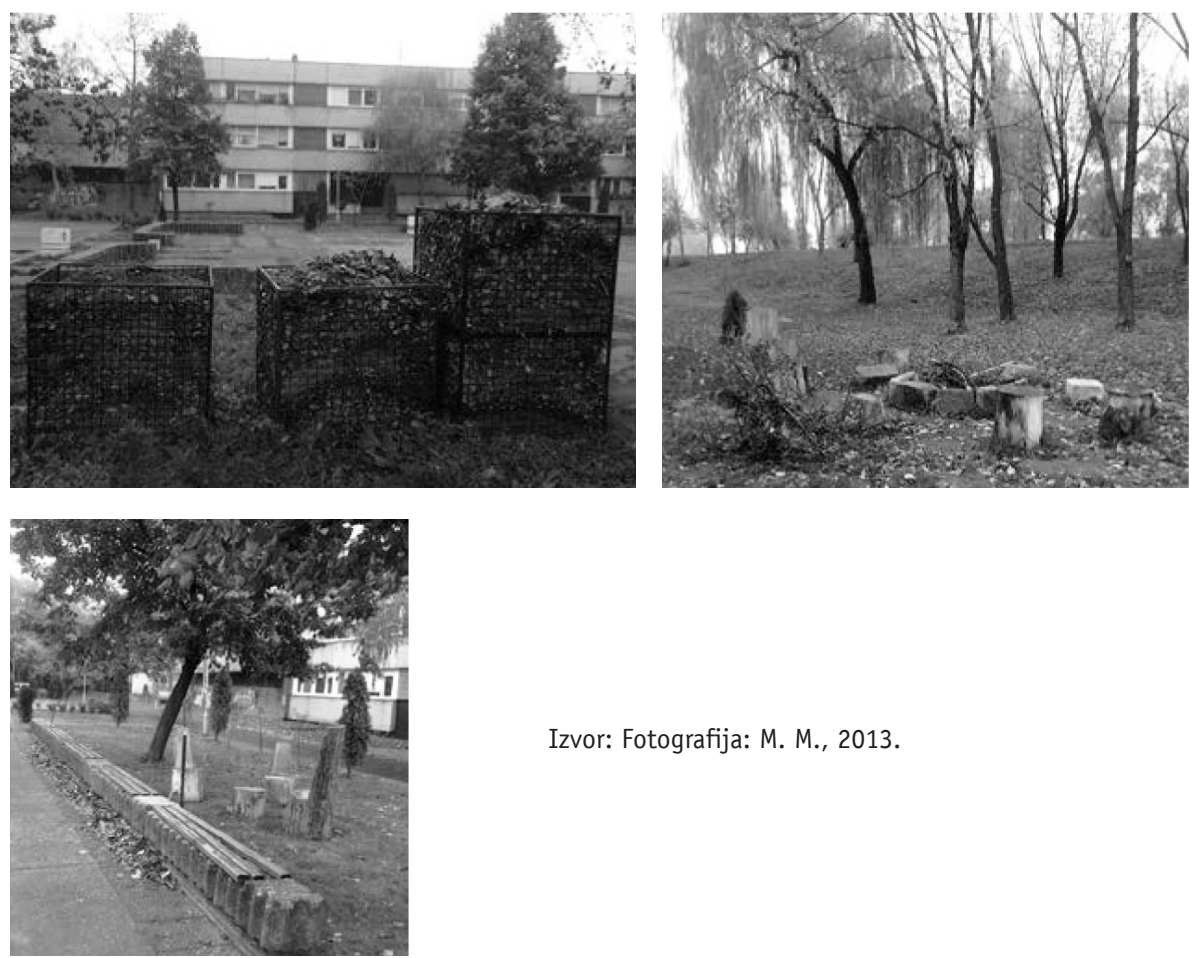

Izvor: Fotografija: M. M., 2013. 


\subsection{Principi međusobnog usaglašavanja - izdvajanje i pripadanje}

Porodične kuće u naselju Šumice pozicionirane su na obodu bloka, prema unutrašnjosti naselja, u skladu sa konceptom stambene zajednice. Po pet tipskih porodičnih kuća formiraju niz koji je prvobitno bio povezan sa slobodnim površinama u bloku. Pad terena je planom iskorišćen za oblikovanje kaskadnog niza i terasasto organizovanje prelazne zone između javne zone bloka i dvorišnih terasa porodičnih kuća (privatna zona). Ova prelazna zona nije bila ograđena, čime je i očuvano i kolektivno pripadanje kuća u nizu široj stambenoj zajednici (naselju). Podzidima koji su predstavljali produžetak kalkanskih ${ }^{4}$ zidova omogućeno je transparentno razdvajanje susednih kuća u nizu, u skladu sa doziranom privatnošću koncepta stembene zajednice. Nakon privatizacije (početkom 1990-ih), vlasnici kuća su bez međusobnog usaglašavanja renovirali svoje objekte, a za pripajanje prelazne zone su se organizovali nakon 2000. godine, i obratili Javnom komunalnom preduzeću „Zelenilo” sa zahtevom da se odvoje od javnog prostora bloka. Ograđivanje živom ogradom odredila je komunalna služba, a stanovnicu su prihvatili to rešenje kao primeren način izdvajanja. Stanovnici kuća u nizu su na poziciji podzida postavili ograde među sobom, odnosno prema svojim prvim susedima pojačavajući distinkciju i unutar niza odnosno privodeći svoj življeni prostor konceptu individualnog stanovanja, a prisvojene platoe održavaju kao svoja dvorišta (Prilog 2.2.).

Prilog 2.2.

Ograđivanje i prisvajanje dvorišnih platoa, kuće u nizu u naselju Šumice, u Beogradu

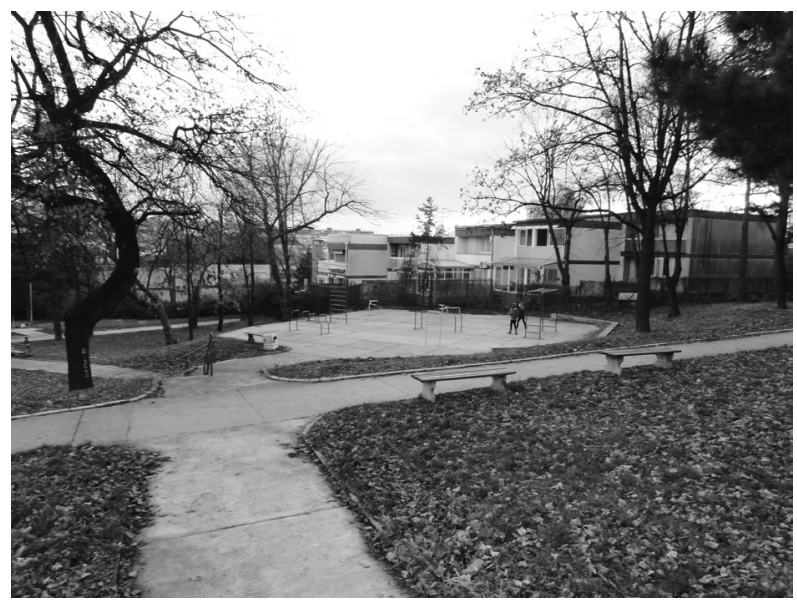

Izvor: Fotografija: M. M., 2012.

Ovaj primer pokazuje prakse izdvajanja i individualizacije u za to pogodnim prostornim strukturama nakon privatizacije i promene modela upravljanja. Za to je, međutim, bilo neophodno da se stanari kuća u nizu organizuju kao grupa - susedstvo. Oni su na osnovu pripadanja jednoj susedskoj celini sproveli zajedničku akciju izdvajanja od šire stambene zajednice.

${ }^{4}$ Kalkanski zid je zid koji razdvaja dve susedne kuće u nizu. 
Moguće mere institucionalne i stručne podrške ovakvim praksama trebalo bi da obuhvate sledeće postupke u cilju olakšanja artikulacije potreba i za izdvajanjem ali i za pripadanjem određenom mestu u naselju:

(1) Identifikovanje prostorne dispozicije koja odstupa od dominantnog prostornog obrasca u okruženju;

(2) Identifikovati segmente sklopa koji se izdvajaju kao celina unutar sklopa;

(3) Identifikovati "dozu" tolerancije razlika između prepoznatih segmenata i načine njihovog usaglašavanja.

\subsection{Označavanje i kontrola zajedničkog prostora}

Primer stambene zgrada Nehruova 216 u novobeogradskom bloku $45^{5}$ pokazuje da su pitanja obezbedivanja ulaza u zgradu ne samo prepoznata, kao pitanja od zajedničkog interesa već i kao prostor kreativnog delanja, budući da je, kao i u mnogim novobeogradskim naseljima, logika administrativnog postavljanja brojeva na zgradama nerazumljiva običnim građanima i otežava snalaženje u prostoru, posebno posetiocima.

Oslikavanje ulaza je jedan od načina da se olakša orijentacija stanovnika i njihovih gostiju, da se pored informacije o adresi stanovanja, objasni kako do tog ulaza doći i lako uočiti ciljano mesto. Stanovnici u bloku 45 opredelili su se da u uglu zajedničkog prostora (ulaznog trema), po uzoru na grafičko rešenje standardizovanih tabli za adrese ulaza u Beogradu, oslikaju uvećan broj 216 (Prilog 2.3.). Broj je pozicioniran tako da se iz veće daljine zgrada lako uočava. Prema rečima stanara, time su ne samo doprineli boljoj vidljivosti zgrade već su i prostor zgrade identifikovali - individualizovali u skladu sa svojim preferencama, što je doprinelo identifikaciji stanara sa stambenom zgrada, kako u fizičkom tako i u socijalnom smislu. Stanari su ispoljili kreativnost i u postavljanju video nadzora, jer je kamera skriveno pozicionirana u broju 1. Pored toga, postavili su i rukohvate na stepeništu, u cilju podizanja bezbednosti, posebno najmlađih i najstarijih suseda.

U odnosu na ovaj primer, moguća fleksibilizacija standarda bi obuhvatila:

(1) identifikovanje zona zajedničkog prostora između polujavnog i poluprivatnog prostora u blizini stambenog sklopa (više stambenih ulaza ili više stambenih objekata);

(2) identifikovati razgraničenja (materijalizacija granica, oznake, broj, naziv, infotable sa napomenama o režimu korišćenja zajedničkog prostora);

(3) identifikovati privremenost i povremenost režima upotrebe prostora.

5 Novobeogradski blokovi 45 i 70 planirani su, projektovani i izvedeni istovremeno kao dve mesne zajednice identičnog prostornog i arhitektonskog rešenja. Ovaj primer organizovane kontrole i kreativnog označavanja zajedničkog prostora (ulaza u stambenu zgradu) nalazi se u zoni malih gustina, dvospratnih i četvorospratnih višeporodičnih stambenih objekata, atrijumskog tipa koje smo opisali u poglavlju 2.1. 
Prilog 2.3.

Kreativan način označavanja i kontrole ulaza, blok 45, Novi Beograd

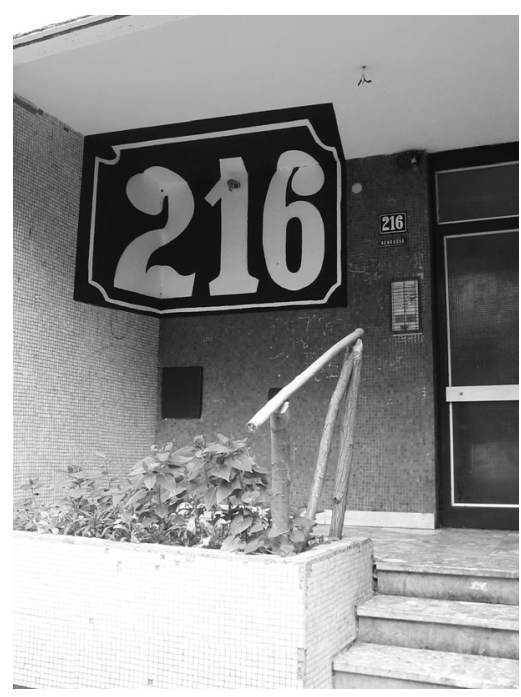

Izvor: Fotografija: M. M., 2011.

\subsection{Gostoljubivo mesto - prakse označavanja polujavnog prostora}

U spontano uređenim prostorima za boravak u otvorenim prostorima naselja moguće je uočiti niz prostornih struktura i povezanih praksi koje u prostoru koji nije ograđen potvrđuje otvorenost kako prema (drugim) ljudima tako i prema prirodnom ambijentu. Na taj način stanovnici keriraju tzv. gostoljubiva mesta, kao mesta slobodne interpretacije značenja - koja nisu standardizovana, konvencijama i pravilima uređene razmene, što ove prostore čini generatorima događaja, delom anegdote malog urbanizma (Bogdanović, 1958.). Gostoljubivo mesto je indikator karaktera komunikacije u naselju, odnosno u susedstvu. To je mesto koje je otvoreno za drugog, za prolaznika, nepoznatog. Mesto koje nastaje u stalnom susretanju različitih stilova života. Konačno, u susedstvu kao savremenoj zajednici kreativne akcije drugih su poželjne, jer to povećava ukupnu atraktivnost susedstva.

Primer uređenja polujavnog prostora u novobeogradskom bloku $62^{6}$ odnosi se na deo zelene površine koji se nalazi se između saobraćajnice i parking prostora, i koji i

\footnotetext{
${ }^{6}$ Specifičnost prostornog koncepta je simetrična makrokompozicija koju čine dva niza stambenih objekata koji prate osovinski postavljenu zonu centra (zona najvišeg stepena javnosti). Spratnost objekata je različita, najveća je uz zonu centra $(P+20)$, a najniža $(P+3)$ na suprotnom kraju gde su planirane škole i predškolske ustanove. Između najviše kule i najnižeg objekta kaskadno se nižu objekti i formiraju jedinstvenu celinu - lamelu. Objekti koji formiraju kaskadni niz međusobno su povezani pešačkom platformom koja predstavlja zajednički prostor lamele. Između dve susedne lamele organizovan je polujavni prostor (tereni za igru dece različitog uzrasta).
} 
po svojoj poziciji pripada i stanovnicima i prolaznicima (Prilog 2.4.). Mesto nije ograđeno, a zasađene biljke omeđene graničnicima označavaju granicu kultivacije (prisvajanja) zelene površine od strane stanovnika. Stanovnici u ovom prostoru samoinicijativno prilagođavaju prostor potrebama prijatnijeg boravka i druženja u naselju, istovremeno ostavljajući poruke u prostoru da je on otvoren i za drugog (suseda, gosta/prolaznika). Postavljeni su trem i fontana, zasađen ružičnjak. Natkriven trem, zaklonjen od saobraćaja ozelenjenim paravanima je struktura koja potvrđuje kulturu okupljanja i gošćenja "pod tremom". Trem se koristi za društvene igre i dogovore, a pored njega u prostoru se, u periodu lepog vremena, nalazi i baštenska garnitura za sedenje (oformljena od različitih garnitura - priloga stanara), a čije neunošenje ukazuje da se prostor doživljava kao „svoj“ i bezbedan, otvoren je i za druge, za nepoznate koji nisu percepirani kao opasnost. Stariji stanovnici blokova trem prepoznaju kao element tradicije (dočekivanje i gošćenje) dok je fontana njihova poruka upućena deci iz kraja da su dobrodošla. Table sa napomenom da voda nije za piće i da je objekat pod video nadzorom ukazuju na kontrolu upotrebe prostora. Ipak, upozorenja da voda nije za piće upućena je vlasnicima kućnih ljubimaca ali i drugim prolaznicima, radi obostrane sigurnosti, što je ujedno i "poruka" koje poziva na kontakt i pokazuje otvorenost zajednice za gosta/ stranca/ drugog.

Kada je reč o aspektu fleksibilizacije standarda u produkciji prostora, smatramo da od ovakvih mesta treba započeti zajedničke akcije uređivanja prostora, kao mesta susretanja kreativaca - građana i profesionalaca, kao polazna tačka uređenja javnih prostora u stambenim naseljima koja su u odgvornosti više aktera (sva tri sektora: javni, civilni i privatni).

Prilog 2.4.

Gostoljubivo mesto u novobeogradskom bloku 62

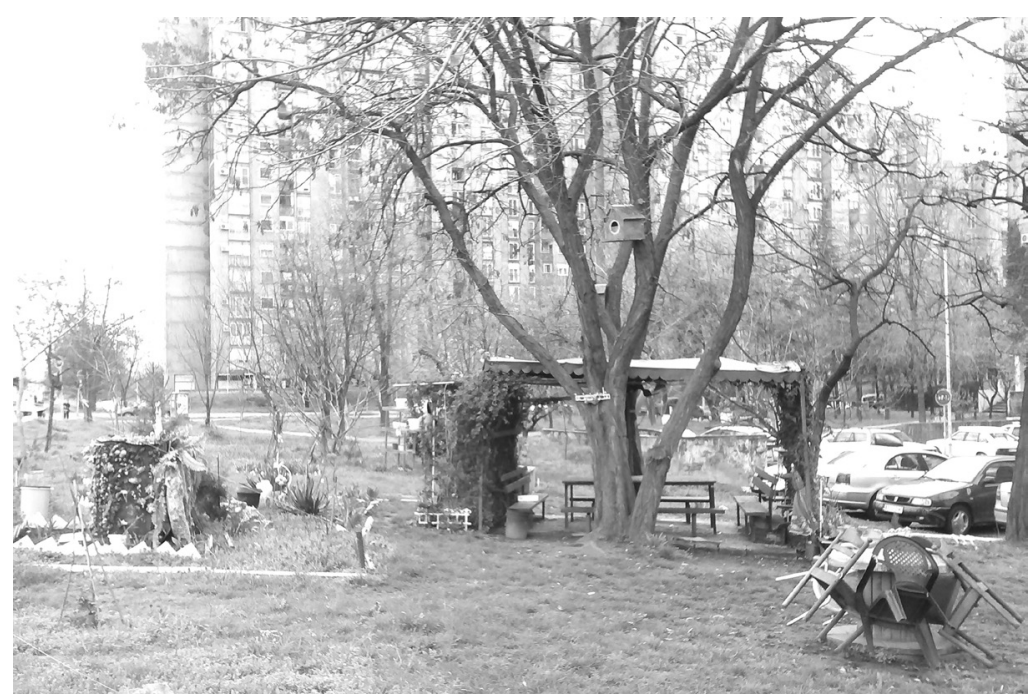

Izvor: Fotografija: M. M., 2013. 


\subsection{Generisanje socijalnog kapitala i odbranjivost javnog prostora}

Akcije sprečavanja izgradnje komercijalnih objekata na parkovskim površinama u stambenim naseljima pokazuju da građani nastoje da utiču na promene u javnom prostoru naselja u kojem žive odnosno koji tangira njihova naselja. Ilustrativan je primer sprečavanja postavljanja balon-hale za mali fudbal u naselju Šumice. Ovaj slučaj izdvajamo zato što način uređenja prostora pokazuje značaj u generisanju građanskog aktivizma, jer su se za odbranu javne površine angažovali stanovnici iz okolnih zgrada susednih mesnih zajednica, a u značajno manjem broju stanovnici mesne zajednice 5, na čijoj teritoriji je ova zelena površina. Njihova pasivnost ishodi iz činjenice da su manje upućeni na pomenute javne površine (ne borave tu i ne prolaze redovno) i ne vide ih "sa svog prozora", kako su sami formulisali. S druge strane, sagledivost prostora i upućenost stanovnika na rekreativne prostore susedne stambene zajednice razvili su osećaj pripadnosti mestu i kod građana koji administrativno ne pripadaju ovoj stambenoj zajednici.

Neposredni sukob između građana i investitora (Centra za kulturu i sport „Šumice”) izazvala je bespravna seča sedam stabala javora ispred Sportskog centra Šumice (izvođač radova firma "Bewine"). Jedan od stanovnika je događaj snimio mobilnim telefonom i "vest" raširio putem društvenih mreža, što je aktivirao veliki broj građana koji nisu stanovnici ovog naselja. Formirana je grupa „Mi volimo Šumice“, koja je potom nizom akcija zadobila medijsku pažnju.

Koristeći činjenicu da je voditeljka radio emisije, jedna stanarka je izveštavala o naporima svojih suseda i promovisala akciju Sportski dan u Šumicama, organizovanu građanskim sredstvima u cilju sprečavanja uzurpacije zelene površine i zaustavljanja krčenja šume stare koliko i samo naselje (Prilog 5.5.).

Svakodnevnim akcijama stanovnika susednih stambenih zajednica u ovom delu parka trajno je sprečeno postavljanje balon-hale. Sekretarijat za inspekcijske poslove je podneo prekršajne prijave protiv investitora i izvođača, a na mestu gde je posečeno drveće gradska služba Zelenilo Beograd posadilo je deset mladica javora, u prisustvu gradskih čelnika. Grupa „Mi volimo Šumice” nastavila je da okuplja, umrežava građane koji se, ma gde da žive suprotstavljaju vandalizmu, a zbog uspeha koji su postigli u Šumicama i ovo mesto smatraju delom svog grada.

Sa planersko-projektanskog stanovišta navedeni primer potvrđuje tezu da u reorganizaciji stambenih zajednica treba imati u vidu prostore koji zbog svoje pozicije mogu angažovati društveni kapital susedstva i razviti kohezione veze i izvan teritorijalno i administrativno određene granice stambene zajednice. Zbog toga je aspekt preglednosti (odbranjivosti) prostora značajan u prostornoj organizaciji naselja i angažovanju društvenog kapitala susedstva. 
Prilog 5.5 .

Organizovana građanska akcija sprečavanja uzurpacije zelene površine i zaustavljanja krčenje šume „Sportski dan u Šumicama”

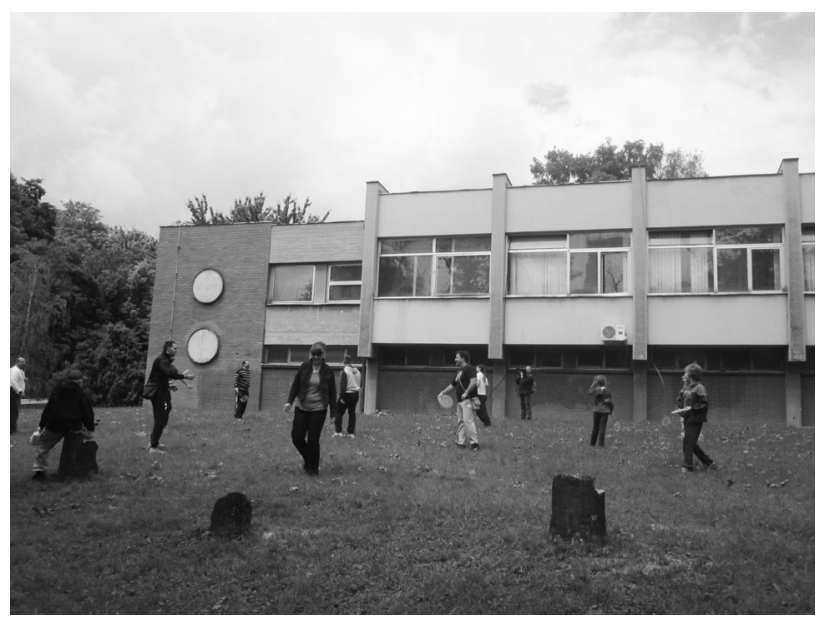

Izvor: Fotografija: M. M., 2012.

\section{Zaključak}

Analizirane prostorne prakse ilustruju procese socio-prostorne distanciranosti u velikim stambenim kompleksima kao bitan element formiranja susedskih odnosa u sprezi sa primenjenim konceptom teritorijalnog gradijenta stambenih zajednica, čime se potvrđuje da je prostor bitan generator komunikacije u susedstvu odnosno bitan resurs prostornih praksi kojima se konstantno odvija (re)produkcija prostora. Iako planerski koncept stambene zajednice velikih rezidencijalnih naselja, inicijalno redukovan kolektivističkim vrednostima doba u kojem je razvijen, nije podrazumevao susedstvo kao dinamično i otvoreno polje socio-prostornih interakcija heterogenih aktera, i u ovim naseljima odvijaju se procesi povezivanja i distanciranja, a samim tim i diverzifikacije susedstva na različitim pozicijama teritorijalnog gradijenta, primer 1 - intervencija u polujavnom prostoru koji je orijentisan prema privatnom prostoru ; primer 2 - zona poluprivatnog (izdvajanje i pripadanje); primer 3 - zona zajedničkog (jedna i/ili više zgrada); primer 4 - zona polujavnog prostora orijentisanog prema javnom (gostoljubivo mesto); Primer 5 - zona javnog (integracija i konektivnost). Dakle, u posmatranim stambenim kompleksima formira se niz susedstva kao unija stanara više zasebnih stambenih jedinica ili sklopova koji su, zbog prostorne blizine upućeni na interakciju, povremeno ili privremeno, a kroz koju se prostorni resursi prepoznaju kao zajednički, i kao takvi markiraju u odnosu na druge, sa većom ili manjom otvorenošću.

Kroz ilustrovane prakse uopčava se produkcija „vanserijskog“ otvorenog prostora u serijskoj, tipiziranoj izgradnji (kolektivne forme ili dominantnog obrasca) naselja, posredstvom kojih stanari prisvajaju prostor kao zajedničko dobro prepoznatog susedstva i definišu njegove granice prema drugom susedstvu ili drugima (nepozna- 
tom, prolazniku i sl.), odnosno reflektuju se sva tri nivoa produkcije prostora u Lefevrovom pristupu (projektovani prostor kao zadata struktura, rutina svakodnevice i kreativne rekonstrukcije), odnosno susedstvo se potvrđuje kao specifičan habitus (obrasci ponašanja stečeni socijalizacijom u određenim strukturnim formama) i autonomno polje prakse (autonomna logika delanja u odnosu na raspoložive resurse aktera u susedstvu).

Razmatrane susedske prakse dobijaju na značaju sa prenosom odgovornosti održavanja i upravljanja zajedničkim prostorima u neposrednom okruženju stana/zgrade na vlasnike odnosno korisnike stanova. Iako ovaj vid građanskog aktivizma u Srbiji nije razvijen, akcije koje zatičemo u naseljima ukazuju na mogućnosti aktiviranja lokalnih resursa u jačanju susedskih odnosa i rešavanju problema naselja, jer se, kao što je već rečeno, u njima prepoznaju nastojanja da se brine o zajedničkom prostoru, da se kontrolišu promene u čitavom naselju, a ne samo u delu naselja ili u privatnom prostoru. Iako se stanari manje više uspešno organizuju na nivou stambene zgrade, udruživanje više stambenih zgrada je još veoma retko. Takva mogućnosti posebno se odnose na velike rezidencijalne celine, ali osim spontanog aktivizma građana koji bi trebalo podsticati, neophodno je i da između građana i institucija postoji adekvatna komunikacija, koja, s jedne starne, treba da bude dovoljno kooperativna i da uvaži želje i potrebe građana, a, s druge strane, da obezbedi poštovanje minimalnih standarda gradnje i kvaliteta stanovanja kao javnog dobra. Dakle, prostorne prakse stanovnika trebalo bi ojačati stručnom i institucionalnom podrškom koja afirmiše sve aktere u produkciji prostora stambenih naselja, uz značajan stepen fleksibilnosti u regulativi zajedničkih resursa.

U ovom pravcu, u radu su samo naznačene moguće akcije fleksibilne artikulacije standarda. Smatramo da se relevantnost ovoga rada nalazi u afirmisanju značaja prostornih praksi građana posvećenih rešavanju problema u održavanju i unapređenju javnih prostora u naselju u kojem žive, a posredstvom kojih proširuju svoj uticaj izvan granica privatne svojine i partikularnog interesa. Za svako društvo je važno da građani svoje akcije preduzimaju u saradnji sa susedima odnosno sa nadležnim institucijama, a upravo to je veoma zapostavljena dimenzija u tranzicijskim društvima u kojima se stihijska privatizacija društvene imovine i prenošenje nadležnosti u oblasti održavanja i upravljanja stambenim zgradama/okruženjem na građane odvija bez dovoljno stručne i institucionalne pomoći radi uspostavljanja/očuvanja bazičnih standarda stanovanja. Ovaj rad se, međutim, nije bavio „problematičnim“ već „dobrim“ primerima, upravo u želji da afirmiše prostorne prakse građana na nivou urbanog susedstva u okvirima kolektivnog tipa stanovanja, kao i činjenicu da je proces socio-prostorne distanciranosti jedna od identitetskih dimenzija takvog susedstva. 


\section{Literatura}

1. Albrow, M. (2000). Traveling beyond local cultures: sociospaces in a global city, in: Eade, J. (ed.). Living the Global City. London: Routledge, pp. 37-55.

2. Brint, S. (2001). Gemeinschaft Revisited: A Critique and Reconstruction of the Community Concept. Sociological Theory, 19 (1): 1-23.

3. Bourdie, P. (1990). The Logic of Practice. Stanford: Stanford University Press.

4. Bogdanović, B. (1958). Mali urbanizam. Sarajevo: Univerzum.

5. Cvejić, S. (Ur.) (2010). Suživot sa reformama: Građani Srbije pred izazovima «tranzicijskog nasleđa». Beograd: ISI.

6. Etzioni, A. (1992). „A Socio-Economic Pers+pective on Friction“, u: Sjostrand, S. E. Institutional Change. Theory and Empirical Findings. New York: M.E.Sharpe.

7. Forrest, R. and Kearns, A. (2001). Social cohesion, social capital and neighborhood. Urban Studies, 38 (12): 2125-2143.

8. Hobs, T. (2006). Čovek i građanin (prevod: Natalija Mićunović). Beograd: Hedone, d.o.o. [Hobbes T. (1991). Men and Citizen (De Homine and De Cive) (prevod sa latinskog na engleski Charles T. Wood, Scott-Craig, Bernard Gert). Indianopolis: Hacket Publishing Company, Inc.].

9. Lefebvre,H. (1991). The Production of Space. Oxford: Blackwell.

10. Jacobs, J. (1964). The Death and Life of Great American Cities: The Feilure of Town Planning. Harmondsworth: Penguin.

11. Milojević, M. (2009). Re-conceptualization of the Idea of Neighborhood in Postsocialist Belgrade. Serbian Architecture Journal, 1 (1): 45-71.

12. Newman, O. (1973). Defensible Space - Crime Prevention Through Urban Design. New York: Macmillan Publishing Co., Inc.

13. Nikezić, Z. (2007). Građena sredina i arhitektura. Beograd: Univerzitet u Beogradu, Arhitektonski fakultet.

14. Novak, V. (ur.) (1958). Stambena zajednica - Porodica i domaćinstvo 1958. Ljubljana: Gospodarsko razstavišče.

15. Paterson, M. (2006). Consumption and Everyday Life (The New Sociology). London, New York: Ruotledge.

16. Petovar, K. and Mojović, Đ. (2006). Condominium Management and Maintenance. Four Strategic Themes for the Housing Policy in Serbia. National Housing Conference "Towards a New National Housing Policy for Serbia«. Belgrade, 6-7 July 2006.

17. Petrović, M. (2004). Sociologija stanovanja. Beograd: ISI FF.

18. Petrović, M. (2008). Istraživanje socijalnih aspekata urbanog susedstva: percepcija stručnjaka na Novom Beogradu. Sociologija, 50 (1): 55-78.

19. Petrović, M. (2009). Transformacija gradova: ka depolitizaciji urbanog pitanja. Beograd: FF ISI.

20. Petrović, M. (2012). Pretpostavke novog modela upravljanja okruženjem u Srbiji. Sociologija, LIV (1): 87-104.

21. Putnam, R. D. (1993). The prosperous community: social capital and community life. The American Prospect, No. 13.

22. Robinson, J. W. (2006). Institution and Home: Architecture as a Cultural Medium. Delft: Techne Press. 
23. Simmel, G. (1997). The Sociology of Space, in: D. Frisby and M. Featherstone (eds). Simmel on Culture. London and Newbury Park, CA: Sage, pp. 137-70.

24. Spasić, I. (2004). Sociologije svakodnevnog života. Beograd: ZUNS

25. Stevenson, D. (2003). Cities and Urban Cultures. Maiden Head: Open University Press.

26. Tonkiss, F. (2005). Space, the City and Social Theory. Oxford: Polity Press.

27. Woolcock, M. (1998). Social capital and economic development: towards a theoretical synthesis and policy framework. Theory and Society, 27 (2).

28. Zakon o održavanju stambenih zgrada, Sl. glasnik Republike Srbije“, br. 44/95, 46/98, 1/01. 
Mina Petrović

University of Belgrade, Faculty of Humanities and Social Sciences, Belgrade, Serbia

e-mail:mipetrov@f.bg.ac.rs

Milica Milojević

University of Belgrade, Faculty of Architecture, Belgrade, Serbia

e-mail:m.milojevic@arh.bg.ac.rs

\title{
Spatial Practices of Designing Desirable Spatial and Social Distance - Reaffirmation of Neighbourhood
}

\begin{abstract}
The paper aims to explore the relation between the concept of housing communities developed within designing and planning practices of residential settlements in the period of dominance of collective values and structures in Belgrade, and spatial practices of their actual users. Thereby it seeks to achieve the reaffirmation of the notion of neighborhood, which was not explicitly recognized in the dominant concept of housing communities and planning of large residential settlements in socialism. In the introductory part, the concept of housing dwellings is defined and then the concept of neighborhood, developed within social sciences. The initial assumption of the analysis is that respecting the principle of territorial gradient in the observed residential ensembles provides the basis for the development of neighborhood as communities of individual persons. In the central part of the analysis, the idea of neighborhood is brought into connection with the production of space, especially with the term spatial practices. Afterwards, based on specific examples of spatial practices in the settlements set up during socialism, residents' activities are shown. They generate cooperation and cohesion, creativity in use of mutual resources, which is the positive effect of spatial structures and their quality. The planning and design of such settlements confirm that they generate neighborly relations in smaller units. It is only to be expected that residents should jointly take care of common rooms in their buildings or corresponding land plots as well as maintain space of common interest for both public and civil sector. In order to reaffirm the neighborhood and the resulting spatial practices which are an important element of the production of space, some suggestions are offered in the domain of planning and designing.
\end{abstract}

Key words: dwelling community, neighbourhood, spatial practices, distance. 